\section{Automobile Industry Needs in Materials Research}

\section{Kathleen C. Taylor}

The demands on the automobile industry in the last decade have been competitive pressures to improve quality, performance and durability, and also exhaust emission control and the need to improve fuel efficiency. Materials technologies are important for meeting these demands. Materials science in the automobile industry captures a large component of today's R\&D effort, both within the car companies and throughout the vast supplier network.

Materials areas at the focus of current R\&D include structural materials, plastics and composites, electronic materials, electrochemical materials, metallic and organic coatings, glass, and catalysts, as well as new materials for manufacturing tools.

What are the trends and needs?

Improved fuel efficiency calls for lighter weight materials in addition to the downsizing of vehicles; durability requires the use of more corrosion-resistant materials. Present trends are the increased use of electrogalvanized steel, plastics, and composite materials. Plastics now comprise more than $200 \mathrm{lb}$ of the weight of each vehicle, and focusing on all polymer-based materials such as elastomers, paints, adhesives and sealants, this number is approximately $400 \mathrm{lb}$. Recently a 12-year joint research agreement was established by GM, Ford, and Chrysler on plastic composite materials for cars and trucks.

As an alternative to metallic parts, plastics must be competitive on the basis of cost, ease of fabrication and bonding, strength, and for outer surfaces, the quality of the surface finish. Plastics must be compatible with all aspects of manufacturing. While plastics have the advantage of corrosion prevention, their high cost must be compensated for through simplification of the manufacturing process, such as a decrease in the number of parts to be assembled.

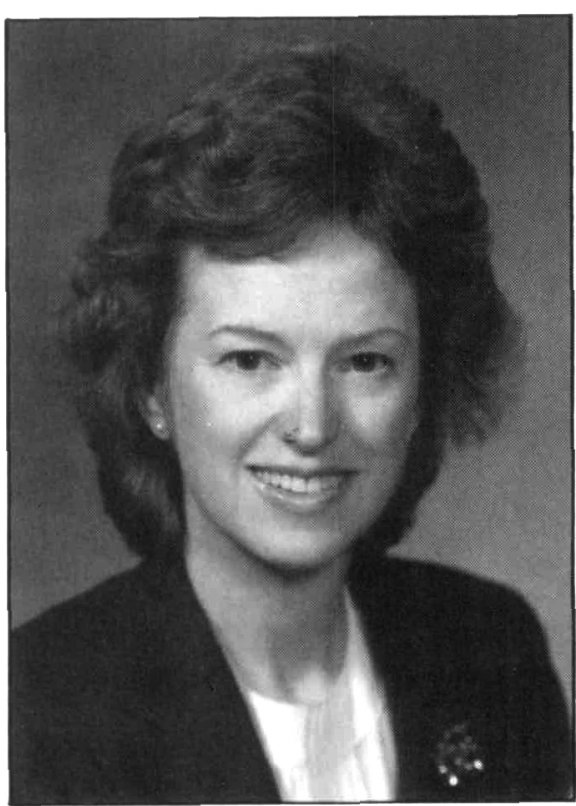

We are looking for lowcost catalysts that do not use rhodium, new protective coatings for both appearance and corrosion protection, durable and easy-to-use adhesives, and long-life batteries.

The promise of advanced ceramics in automobiles is for higher engine efficiency through thermal insulation, improvements in friction and wear, and weight reduction. However, many processing and reliability problems must be solved before ceramics can be applied broadly. The major deficiencies of ceramics at the present time as substitutes for metals are low reliability (brittle failure) and cost of fabrication.

Improved vehicle performance and emission control have been tied to new electronics. The electronic content per vehicle averages $\$ 500$ per car and is expected to more than double by 1995 . Every car now has a computer which controls the air-fuel ratio for optimum performance of the emission control system. New electronically controlled features include anti-lock brakes and on-board diagnostics. Collision avoidance systems and heads-up displays are under development. The trend is toward increased electronic control and, with that, increased electrical demand.

Needs and opportunities for new materials and components will expand as we continue to seek improvements in weight reduction, durability, and design. Right now we are looking for low-cost catalysts that do not use rhodium, new protective coatings for both appearance and corrosion protection, durable and easy-to-use adhesives, and long-life batteries. There is a strong interest in new batteries for electric vehicles. The advent of an alternate vehicle fuel such as methanol could lead to other new technologies. For example, highly efficient fuel cells might be adopted to provide auxiliary power. Fuel cell technology will require that efficient low-cost membranes and electrocatalysts be available. The projected replacement of the freon CFC-12 in automobile air conditioners with CFC-134a has created a need for a new lubricant.

The improved performance and durability of new materials have increased the challenge the engineer faces to develop accelerated test procedures that accurately predict the performance of materials. Testing becomes more difficult as materials properties are improved. The payoff would be enormous if we could predict performance based on knowledge of chemicalphysical characteristics and operating parameters.

The reward can be great for new materials applications in the automobile industry. Worldwide, 45 million new vehicles are built each year. The automobile industry provides a tremendous opportunity for U.S. materials researchers to impact on the U.S. economy as well as the personal reward of seeing new jobs created as a result of successful research projects.

Kathleen C. Taylor is head of the Physical Chemistry Department at GM Research Labomatories at Warren, Michigan. 